\title{
Predictors of Nipple-Areolar Complex Involvement by Breast Carcinoma: Histopathologic Analysis of 787 Consecutive Therapeutic Mastectomy Specimens
}

\author{
Jianli Wang, MD' ${ }^{1}$, Xiuli Xiao, $\mathrm{MD}^{2}$, Jianmin Wang, $\mathrm{MD}$, $\mathrm{PhD}^{3}$, Naazneen Iqbal, $\mathrm{MD}^{4}$, Laurie Baxter, $\mathrm{MS}^{4}$, \\ Kristin A. Skinner, $\mathrm{MD}^{5}$, David G. Hicks, $\mathrm{MD}^{4}$, Steven I. Hajdu, $\mathrm{MD}^{6}$, and Ping Tang, $\mathrm{MD}, \mathrm{PhD}^{4}$ \\ ${ }^{1}$ Department of Pathophysiology, Shandong University School of Medicine, Shandong, China; ${ }^{2}$ Department of Pathology, \\ Luzhou Medical College, Luzhou, China; ${ }^{3}$ RTI Health Solution, Research Triangle Park, NC; ${ }^{4}$ Departments of Pathology, \\ University of Rochester Medical Center, Rochester, NY; ${ }^{5}$ Department of Surgical Oncology, University of Rochester \\ Medical Center, Rochester, NY; ${ }^{6}$ Pathology Consultants, Los Angles, CA
}

\begin{abstract}
Background. Breast-conserving therapy (BCT) is an accepted therapeutic option for most breast cancer patients. However, mastectomy is still performed in 30-50\% of patients undergoing surgeries. There is increasing interest in preservation of the nipple and/or areola in hopes of achieving improved cosmetic and functional outcomes; however, the oncologic safety of nipple-areolar complex (NAC) preservation is a major concern. We sought to identify the predictive factors for NAC involvement in breast cancer patients.
\end{abstract}

Methods. We analyzed the rates and types of NAC involvement by breast carcinoma, and its association with other clinicopathologic features of the tumors in 787 consecutive therapeutic mastectomies performed at our institution between 1997 and 2009.

Results. Among these, 75 cases (9.5\%) demonstrated NAC involvement. Only $21(28 \%)$ of 75 of cases with NAC involvement could be identified grossly by inspection of the surgical specimen (seven of these had been clinically identified). NAC involvement was most significantly associated with tumors located in all four quadrants $(P<0.0001)$, tumors $>5 \mathrm{~cm}$ in size $(P=0.0014$ for

Jianli Wang and Xiuli Xiao contributed equally to this article.

(C) The Author(s) 2011. This article is published with open access at Springerlink.com

First Received: 6 May 2011;

Published Online: 18 October 2011

P. Tang, MD, PhD

e-mail: ping_tang@urmc.rochester.edu invasive carcinoma and $P=0.0032$ for in-situ carcinoma), grade 3 tumors $(P=0.0192)$, tumors with higher nuclear grades $(P=0.0184)$, and tumors with HER2 overexpression $(P=0.0137)$.

Conclusions. On the basis of our findings, we have developed a mathematical model that is based on the extent and location of the tumor, HER2 expression, and nuclear grade that predicts the probability of NAC involvement by breast cancer. This model may aid in preoperative planning in selecting appropriate surgical procedures based on an individual patient's relative risk of NAC involvement.

After the results of the NSABP B-06 study were reported, the National Institutes of Health released a consensus statement on the "Treatment of Early-Stage Breast Cancer" stating that "breast conservation treatment is an appropriate method of primary therapy for the majority of women with Stage I and II breast cancer and is preferable because it provides survival equivalent to total mastectomy and axillary dissection while preserving the breast". ${ }^{1,2}$ As a result, breast-conserving therapy (BCT) is an accepted therapeutic option for most breast cancer patients. ${ }^{3}$ However, mastectomy is still performed in $30-50 \%$ of patients undergoing surgery for breast cancer, either because the patient is not thought to be a candidate for BCT or because of patient preference. Many women undergo immediate reconstruction at the time of their mastectomy, and skinsparing mastectomy (SSM) is routinely performed in this setting. SSM, which removes all breast tissue, the nippleareola complex (NAC), and biopsy scar if present, has been proven to be oncologically safe compared to conventional non-SSM. ${ }^{4}$ There is increasing interest in preservation of 
the nipple and/or areola in hopes of achieving improved cosmetic and functional outcomes. ${ }^{5-8}$ Studies have shown that the rates of NAC involvement vary from 0 to $58 \% .^{9-11}$ However, these early studies may not serve as a reliable guide for current practice, as the indications for mastectomy have shifted from being the only choice for all breast cancer patients to being used primarily for larger and multicentric tumors, tumors with multiple positive margins, or recurrent tumors. Clearly, NAC removal may not be necessary for all patients undergoing mastectomy. Nipple-sparing mastectomy (NSM) as a potential alternative to SSM may be suitable only for a small and ill-defined group of candidates who have small solitary and/or peripheral tumors. ${ }^{12-14}$ Because NSM does leave behind possible occult nipple involvement by primary tumor and ductal tissue that may become the origin for new cancer, its oncologic safety remains controversial.

This current study utilized the therapeutic SSM specimens from a large retrospective cohort of patients in which the NAC were uniformly processed and entirely embedded for microscopic examination. We intended to investigate the frequency of occult NAC involvement in this unselected population of patients in this postmammogram era; the types of lesions that involve the NAC; and the clinicopathologic factors most frequently associated with NAC involvement. Finally, we sought to propose a model that may predict NAC involvement with reasonable accuracy on the basis of our current data.

\section{METHODS}

Seven hundred eighty-seven consecutive unselected therapeutic mastectomies from the files of the Department of Pathology at the University of Rochester Medical Center between 1997 and 2009 were identified. These included 21 cases with clinically $(n=7)$ or grossly identified $(n=21$, including the seven clinically identified cases) NAC involvement. All mastectomy specimens were inked and sectioned from medial to lateral into no greater than $1-\mathrm{cm}-$ thick tissue sections and grossly examined. The nipples were uniformly shaved, sectioned at 2-3-mm intervals vertically, and submitted perpendicularly for microscopic examination, and the areolas were shaved and submitted en face. The identification of tumor cells in these sections was considered as NAC involvement. Clinical and pathologic factors including patient age, tumor location (e.g., upper inner, upper outer, lower inner, lower outer, or central with or without other quadrants; many tumors involved more than one quadrant), tumor type (ductal carcinoma-in-situ [DCIS], invasive ductal carcinoma [IDC], invasive lobular carcinoma [ILC], lobular carcinoma-in-situ [LCIS], or any combination of the above), multifocality (defined as two or more tumor foci present $>1 \mathrm{~cm}$ apart from each other), tumor size (divided into four subgroups: $<1 \mathrm{~cm}, 1-2 \mathrm{~cm}, 2-5 \mathrm{~cm}$, and, $>5 \mathrm{~cm}$ ), histological grade (according to the modified Bloom-Richardson grading system), nuclear grade (using the 3-tier grading system), expression of estrogen receptor (ER), progesterone receptor (PR), and HER2 (ER and PR recorded as Allred scores, and HER2 recorded according to new American Society of Clinical Oncology/College of American Pathologists guidelines, which scores as a positive stain when $>30 \%$ of invasive tumor cells have uniform strong membrane staining), and lymph node status (recorded as positive or negative) were reviewed and recorded.

Statistical analysis was performed to compare tumors with or without nipple involvement. Apart from the descriptive analysis presented by percent of tumors with or without nipple involvement in each subgroup, the $P$ values from Fisher's exact test were provided as index to indicate the difference between subgroups on the proportion of cancers with nipple involvement. The logistic regression was used to develop a model to predict the probability of cancer with nipple involvement under different conditions.

\section{RESULTS}

Patient demographics and the clinicopathologic characteristics of the 787 mastectomy specimens are listed in Table 1. Among the 787 cancers treated with mastectomy, 488 were IDC, 197 were DCIS, 63 were ILC, 22 were mixed IDC and ILC, 13 were LCIS, 3 were malignant or borderline phyllodes tumors, and one was a myofibroblastic sarcoma. In 75 cases $(9.5 \%)$, there was NAC involvement by carcinoma demonstrated microscopically. Three cases of intraductal papilloma in the NAC and three cases with other benign lesions (neuroma, adenoma and trachoma) identified in NAC were not included in the statistical analysis. Among the 75 cases with microscopically identified NAC involvement, only 21 cases $(28 \%)$ were identified clinically and/or grossly (Table 2).

Mammary Paget disease was the most common nipple lesion in our study with 25 cases (33\%), followed by 17 DCIS (23\%), 15 IDC (20\%), 11 LCIS (15\%), four lymphovascular invasion (5\%), and three ILC (4\%) (Table 2). Less than a third of cases of Paget disease were identified clinically, and about half of the cases of Paget disease were identified grossly, which accounted for half of all grossly identified NAC lesions. Paget disease was the only lesion that was identified clinically.

NAC involvement was most significantly associated with tumor location $(P<0.0001)$. Tumors that were located in 1-3 quadrants were much less likely to have NAC involvement (4-10\%) compared to tumors that were centrally located $(21 \%)$ or located in all four quadrants 
TABLE 1 Clinicopathologic features of breast cancer in the current study

\begin{tabular}{ll}
\hline Characteristic & Value \\
\hline Total cases & 787 \\
Types of tumors in breast & \\
DCIS & 197 \\
IDC & 488 \\
ILC & 63 \\
IDC + ILC & 22 \\
LCIS & 13 \\
Phyllodes tumor & 3 \\
Myofibroblastic sarcoma & 1 \\
Mean patient age, y & 56.88 \\
Mean tumor size (invasive) (cm) & 2.3084 \\
Mean tumor size (in situ) $(\mathrm{cm})$ & 2.8021 \\
Positive lymph node/total cases & $246 / 646(30 \%)$ \\
Tumors in NAC & $75 / 787(9.53 \%)$ \\
\hline
\end{tabular}

TABLE 2 Nipple lesions observed clinically, grossly, and microscopically

\begin{tabular}{llll}
\hline Lesion & Clinical & Gross & Microscopic \\
\hline Total no. & 7 & 21 & 75 \\
Mammary Paget disease & $7(100 \%)$ & $12(57 \%)$ & $25(33 \%)$ \\
DCIS & 0 & $1(4.5 \%)$ & $17(23 \%)$ \\
IDC & 0 & $5(24 \%)$ & $15(20 \%)$ \\
LCIS & 0 & $2(10 \%)$ & $11(15 \%)$ \\
Lymphatic involvement & 0 & $1(4.5 \%)^{\mathrm{a}}$ & $4(5 \%)$ \\
ILC & 0 & 0 & $3(4 \%)$
\end{tabular}

${ }^{a}$ In this case, the tumor was $3.8 \mathrm{~cm}$, grossly abutting the NAC; thus, it was grossly noted as NAC involvement. Under the microscope, the only finding from the two sections (perpendicular sections of the nipple and the shaved section of areolar) was lymphovascular invasion

(34\%). Tumors $>5 \mathrm{~cm}$ in size were more likely to have nipple involvement for both in situ $(18 \%, P=0.0032)$ and invasive carcinomas $(20 \%, P=0.0014)$ than smaller tumors $(6-10 \%$ for in situ tumors and $7-8 \%$ for invasive tumors, respectively). NAC involvement was also significantly associated with high histological grade $(P=$ $0.0192)$ and nuclear grade $(P=0.0184)$. HER 2 positivity was strongly associated with NAC involvement $(7 \%$ in HER2 negative vs. $18 \%$ in HER2 positive tumors, $P=0.0137)$. Lymph node involvement was also associated with NAC involvement ( $8 \%$ in negative vs. $14 \%$ in positive tumors, $P=0.0331$ ). Other clinicopathologic factors including patient age, tumor type, multifocality, and expression levels of ER and PR were not associated with NAC involvement (Table 3).

Among the factors that were associated with NAC involvement, tumor location, tumor HER2 status and nuclear grade are often known preoperatively with reasonable accuracy (Table 4). We generated a predictive table based on a mathematical model to predict the probability of NAC involvement by breast cancer using these three factors (Table 5). The probability for NAC involvement is lowest $(1.7 \%)$ when the tumor is located in one quadrant, has a low nuclear grade and is HER2 negative; and highest $(66 \%)$ when the tumor is located in all four quadrants, has a high nuclear grade and is HER2 positive.

\section{DISCUSSION}

Most studies regarding the rate of NAC involvement by breast carcinomas are from the premammogram screening era, and thus may not reflect the current rate of NAC involvement. Also, the shift from mastectomy to breast conservation surgery, variations in patient population and in tissue processing for the NAC may also impact the observed rates of NAC involvement. A small study in 1989 of 33 cases of mostly multicentric, incompletely resected and recurrent tumors, tumors $>5 \mathrm{~cm}$ or with retracted nipple showed a rate of NAC involvement of $58 \% .^{10} \mathrm{~A}$ similar rate of $50 \%$ of NAC involvement was also observed by Andersen and Pallesen in $1978 .{ }^{15}$ Both studies examined multiple transverse or vertical sections from the nipple. On the other hand, a study of 26 cases with tumors that were at least $2.5 \mathrm{~cm}$ from the areola and nipple showed no NAC involvement microscopically. ${ }^{11}$ In the current study, the rate of NAC involvement is $9.5 \%$, which is compatible with prior studies of 12-23\% NAC involvement. ${ }^{9,16,17}$ Laronga et al. reported that $5.6 \%$ of their 326 cases showed involvement of the NAC, but they had removed cases that had clinical NAC involvement. ${ }^{18}$ Also, many studies reported before routine mammographic screening and the use of BCT would have included smaller and peripheral tumors in their mastectomy series, which would likely lower the rate of NAC involvement. ${ }^{11,18}$ Sampling technique is another factor that affects the rate of reported nipple involvement. The traditional one sagittal section of the nipple is likely to underestimate occult NAC involvement compared to the microscopic examination of multiple coronal or vertical sections of the nipple that was used in our study and in others. ${ }^{10,15,19}$

Tumor size, tumor location, and lymph node status are three pathologic factors consistently shown to be associated with NAC involvement. ${ }^{18,20,21}$ This was confirmed in our study. We did not have information on the distance between tumor and nipple in our study, though many studies have shown that it is an important factor affecting the rate of NAC involvement. ${ }^{11,18,22}$ Lagios et al. confirmed this association with invasive carcinomas, but not 
TABLE 3 Comparison of NAC-negative and NAC-positive cases of breast cancer

\begin{tabular}{|c|c|c|c|}
\hline Characteristic & $\begin{array}{l}\text { NAC } \\
\text { negative } \\
\text { ( } 712 \text { cases) }\end{array}$ & $\begin{array}{l}\text { NAC } \\
\text { positive } \\
\text { ( } 75 \text { cases) }\end{array}$ & $P$ value \\
\hline Age, year (787 cases) & 712 cases & 75 cases & 0.8532 \\
\hline$<40$ (77 cases $)$ & $92 \%$ & $8 \%$ & \\
\hline 40-60 (417 cases) & $90 \%$ & $10 \%$ & \\
\hline$>60(293$ cases $)$ & $90 \%$ & $10 \%$ & \\
\hline Tumor location (771 cases) & 696 cases & 75 cases & $<0.0001$ \\
\hline 1 quadrant (382 cases) & $96 \%$ & $4 \%$ & \\
\hline 2 quadrants (200 cases) & $92 \%$ & $9 \%$ & \\
\hline 3 quadrants (30 cases) & $90 \%$ & $10 \%$ & \\
\hline 4 quadrants ( 35 cases) & $66 \%$ & $34 \%$ & \\
\hline Central (124 cases) & $79 \%$ & $21 \%$ & \\
\hline Tumor type (787 cases) & 712 cases & 75 cases & 0.4574 \\
\hline DCIS (197 cases) & $90 \%$ & $10 \%$ & \\
\hline IDC (488 cases) & $91 \%$ & $9 \%$ & \\
\hline ILC (54 cases) & $89 \%$ & $11 \%$ & \\
\hline IDC + ILC (31 cases) & $81 \%$ & $19 \%$ & \\
\hline LCIS (13 cases) & $92 \%$ & $8 \%$ & \\
\hline Phyllodes tumor ( 3 cases) & $100 \%$ & $0 \%$ & \\
\hline Myofibroblastic SA (1 case) & $100 \%$ & $0 \%$ & \\
\hline Multifocality (784 cases) & 708 cases & 76 cases & 0.1658 \\
\hline No (629 cases) & $91 \%$ & $9 \%$ & \\
\hline Yes (155 cases) & $88 \%$ & $12 \%$ & \\
\hline $\begin{array}{l}\text { Size-invasive tumors } \\
\quad \text { (769 cases) }\end{array}$ & 701 cases & 68 cases & 0.0014 \\
\hline$<1 \mathrm{~cm}$ (301 cases) & $92 \%$ & $8 \%$ & \\
\hline 1 to $<2 \mathrm{~cm}$ (161 cases) & $93 \%$ & $7 \%$ & \\
\hline 2 to $5 \mathrm{~cm}$ (214 cases) & $93 \%$ & $7 \%$ & \\
\hline$>5 \mathrm{~cm}$ (93 cases) & $80 \%$ & $20 \%$ & \\
\hline $\begin{array}{l}\text { Size of in situ tumors } \\
\text { (741 cases) }\end{array}$ & 672 cases & 69 cases & 0.0032 \\
\hline$<1 \mathrm{~cm}$ ( 232 cases $)$ & $94 \%$ & $6 \%$ & \\
\hline 1 to $<2 \mathrm{~cm}$ ( 125 cases $)$ & $90 \%$ & $10 \%$ & \\
\hline 2 to $5 \mathrm{~cm}$ (261 cases) & $92 \%$ & $8 \%$ & \\
\hline$>5 \mathrm{~cm}(123$ cases $)$ & $81 \%$ & $18 \%$ & \\
\hline $\begin{array}{l}\text { Histologic grade } \\
\text { (473 cases })\end{array}$ & 429 cases & 44 cases & 0.0192 \\
\hline 1 (129 cases) & $96 \%$ & $4 \%$ & \\
\hline 2 (181 cases) & $91 \%$ & $9 \%$ & \\
\hline 3 (163 cases) & $87 \%$ & $14 \%$ & \\
\hline Nuclear grade (632 cases) & 573 cases & 59 cases & 0.0184 \\
\hline 1 (98 cases) & $96 \%$ & $4 \%$ & \\
\hline 2 (290 cases) & $92 \%$ & $8 \%$ & \\
\hline 3 (244 cases) & $87 \%$ & $13 \%$ & \\
\hline $\begin{array}{l}\text { Estrogen receptor } \\
\quad(512 \text { cases })\end{array}$ & 462 cases & 50 cases & 0.9334 \\
\hline Negative (131 cases) & $89 \%$ & $11 \%$ & \\
\hline Positive (381 cases) & $91 \%$ & $9 \%$ & \\
\hline
\end{tabular}

TABLE 3 continued

\begin{tabular}{llll}
\hline Characteristic & $\begin{array}{l}\text { NAC } \\
\text { negative } \\
(712 \text { cases })\end{array}$ & $\begin{array}{l}\text { NAC } \\
\text { positive } \\
(75 \text { cases })\end{array}$ & $P$ value \\
\hline $\begin{array}{l}\text { Progesterone receptor } \\
\quad \text { 511 cases })\end{array}$ & 461 cases & 50 cases & 0.2588 \\
Negative (175 cases) & $87 \%$ & $13 \%$ & \\
Positive (336 cases) & $92 \%$ & $8 \%$ & \\
HER2 overexpression (466 cases) & 423 cases & 43 cases & 0.0137 \\
Equivocal $(1$ case $)$ & $100 \%$ & $0 \%$ & \\
Negative (387 cases) & $93 \%$ & $7 \%$ & \\
Positive (78 cases) & $82 \%$ & $18 \%$ & \\
Lymph node status $(646$ cases) & 579 cases & 67 cases & 0.0331 \\
Negative (399 cases) & $366(92 \%)$ & $33(8 \%)$ & \\
Positive (247 cases) & $213(86 \%)$ & $34(14 \%)$ & \\
\hline
\end{tabular}

TABLE 4 Logistic regression to predict NAC involvement by tumors $^{\mathrm{a}}$

\begin{tabular}{lrlrr}
\hline Parameter & Estimate & $\begin{array}{l}\text { Standard } \\
\text { error }\end{array}$ & Wald $\chi^{2}$ & $P>\chi^{2}$ \\
\hline $\begin{array}{l}\text { Intercept } \\
\text { Two-quadrant } \\
\quad \text { involvement }\end{array}$ & -4.0670 & 0.6599 & 37.9797 & $<0.0001$ \\
$\begin{array}{l}\text { Three-quadrant } \\
\quad \text { involvement }\end{array}$ & 1.1669 & 1.1390 & 1.0494 & 0.3056 \\
$\begin{array}{l}\text { Four-quadrant } \\
\text { involvement }\end{array}$ & 3.2843 & 0.6635 & 24.5053 & $<0.0001$ \\
$\quad$ Central location & 2.2656 & 0.5148 & 19.3679 & $<0.0001$ \\
HER2 positive & 0.7979 & 0.4398 & 3.2918 & 0.0696 \\
Nuclear grade 2 & 0.1695 & 0.6163 & 0.0757 & 0.8732 \\
Nuclear grade 3 & 0.0013 & 0.6208 & 1.1348 & 0.2867 \\
\hline
\end{tabular}

${ }^{\mathrm{a}}$ Intercept $=\log (P /(1-P))$ for a reference patient. The reference patient is defined as the patient having zero on all of the variables. In our case, the reference patient is the patient with a tumor that has one quadrant involvement, no central location, negative for HER2 overexpression, and a nuclear grade of one. Thus, in our case, $-4.0670=\log (P /(1-P))$ where $P=1.68 \%$. It means for a reference patient, her chance of NAC involvement is $1.68 \%$. $P$ indicates the probability of the NAC involvement

with DCIS. ${ }^{22}$ Routine gross measurement of the distance from tumor mass to nipple is not always reliable, and this is especially true in cases that involve DCIS, which often present beyond grossly identifiable lesions.

HER2 overexpression in our study was predictive for NAC involvement, with a $P$ value of 0.0137 . Brachtel et al. also showed that HER2 overexpression is associated with NAC involvement. ${ }^{23}$ Among the 177 cases with HER2 information in their study, 43 cases had NAC involvement, 16 of 43 of which had HER2 overexpression, resulting in a rate of $37 \%$. In the current study, among the 43 cases with NAC involvement that had HER2 testing, 14 had HER2 
TABLE 5 Probability of NAC involvement by logistic regression model $^{\mathrm{a}}$

\begin{tabular}{|c|c|c|c|}
\hline Tumor location & HER2 & Nuclear G & Probability $(\%)$ \\
\hline 1 quadrant & - & 1 & 1.7 \\
\hline 1 quadrant & - & 2 & 2.0 \\
\hline 1 quadrant & - & 3 & 3.2 \\
\hline 1 quadrant & + & 1 & ND \\
\hline 1 quadrant & + & 2 & 4.3 \\
\hline 1 quadrant & + & 3 & 6.9 \\
\hline 2 quadrants & - & 1 & 5.6 \\
\hline 2 quadrants & - & 2 & 6.5 \\
\hline 2 quadrants & - & 3 & 10.2 \\
\hline 2 quadrants & + & 1 & 11.5 \\
\hline 2 quadrants & + & 2 & 13.4 \\
\hline 2 quadrants & + & 3 & 20.2 \\
\hline 3 quadrants & - & 1 & ND \\
\hline 3 quadrants & - & 2 & 6.1 \\
\hline 3 quadrants & - & 3 & 9.6 \\
\hline 3 quadrants & + & 1 & ND \\
\hline 3 quadrants & + & 2 & 12.6 \\
\hline 3 quadrants & + & 3 & 19.1 \\
\hline 4 quadrants & - & 1 & 31.4 \\
\hline 4 quadrants & - & 2 & 35.1 \\
\hline 4 quadrants & - & 3 & 47.0 \\
\hline 4 quadrants & + & 1 & ND \\
\hline 4 quadrants & + & 2 & ND \\
\hline 4 quadrants & + & 3 & 66.3 \\
\hline Central & - & 1 & 14.2 \\
\hline Central & - & 2 & 16.4 \\
\hline Central & - & 3 & 24.2 \\
\hline Central & + & 1 & ND \\
\hline Central & + & 2 & 30.3 \\
\hline Central & + & 3 & 41.5 \\
\hline
\end{tabular}

$N D$ no data (the data set does not include this kind of cancer, so its probability cannot be predicted)

${ }^{\text {a }} 1$ xbeta $=(-4.0670+$ location + HER $2+$ nuclear grade $)$; probability of NAC involvement $=[\exp ($ xbeta $) /(1+\exp ($ xbeta $))]$

overexpression (33\%). The association of HER2 positivity with NAC involvement may be related to the presence of mammary Paget disease, which accounts for one of three of our NAC involvement cases. We have shown in a previous study that HER2 overexpression is one of the critical factors in predicting mammary Paget disease, which was excluded from the study of Brachtel et al. ${ }^{23,24}$ Heregulin- $\alpha$, a HER-receptor family ligand and motility factor produced by normal epidermal keratinocytes, may play a role in the pathogenesis of Paget disease. ${ }^{25}$ The binding of heregulinalpha to the HER2-receptor complex on Paget cells may serve as a chemotactic signal and result in migration of tumor cells into the overlying nipple epidermis.
We also observed that Paget disease, DCIS and IDC are the most common types of lesions that involve NAC, consistent with many prior studies. ${ }^{10,16,26}$ A higher nuclear grade tended to be associated with all types of NAC involvement, with the exception of lobular carcinomas (data not shown), consistent with prior studies. ${ }^{22}$ Luttges et al. have shown that multicentricity and multifocality correlated with NAC involvement. ${ }^{27}$ We did observe a statistically significant difference in NAC involvement between tumors present in 1-3 quadrants and tumors present in all 4 quadrants, but we did not confirm multifocality to be associated with NAC involvement, which was the observation by Brachtel et al. ${ }^{23}$

Currently, SSM is being used in most centers, including ours, which allows the removal of all breast tissue and the NAC, but preserves most of the native skin enveloping the breast. ${ }^{4}$ Because NAC involvement is present in only a small percentage of breast cancers, some believe that NSM, which preserves the NAC and may provide better cosmeses and functional results, may be an appropriate alternative for many patients undergoing mastectomy with immediate reconstruction. ${ }^{5-7,27-29}$ Because most of the NAC involvement occurs within the nipple and not the areola, Simmons et al. suggested areolar-sparing mastectomy with removal of nipple while preserving the areola as an alternative to NSM. ${ }^{21}$ To exclude any patient with occult nipple involvement in this setting, intraoperative pathologic evaluation of retroareolar en-face margin or NAC core biopsy have been used in many centers. ${ }^{13,30}$ However, these techniques are not perfect; and there are still both false positive and false negative cases associated with them. $^{23,31}$ Intraoperative retroareolar en-face margin assessment may be used to detect occult tumor involvement in patients undergoing NSM. ${ }^{14,23}$ Nipple needle core biopsies have also been performed to evaluate possible occult NAC involvement intraoperatively. ${ }^{13}$

The ability to accurately predict NAC involvement preoperatively can help clinicians and patients to choose the proper surgical procedure. Vyas et al. found that tumors $2.5 \mathrm{~cm}$ away from the NAC are predictive for no nipple involvement. ${ }^{32}$ Recurrence rate in the NAC was found to be low in patients who had early stage tumors and whose tumor was more than the $2 \mathrm{~cm}$ away from the NAC. ${ }^{14} \mathrm{We}$ previously proposed that immunopathologic patterns strongly associated with mammary Paget disease depend upon the underlying tumor type (ER negative, PR negative, and HER2-positive for DCIS and HER2-positive for IDC). ${ }^{24}$ Schecter et al. proposed a predictive model for NAC involvement with $92 \%$ sensitivity and $77 \%$ specificity based on mammographic distance between tumor and nipple, tumor size, and pathologic staging in a small study of 31 cases. $^{33}$ Rusby et al. have reported a similar predictive model on the basis of a study of 130 patients. $^{34}$ 
Gulben et al. recently reported that tumor location, positive lymph nodes, and lymphatic vascular invasion were the most important risk factors; and patients with two or three risk factors had a 50\% rate of NAC involvement versus only $8 \%$ in patients with one or no risk factors. ${ }^{35}$

In this study, we have shown that NAC involvement is not a rare event, and is strongly associated with tumor location, tumor size, histological grade, and HER2 overexpression. The predictive model we propose here aims to provide some guidance for patients and clinicians in presurgical planning, in conjunction with intraoperative evaluation of retroareolar en-face margin, to selective patients who are suitable for NSM.

ACKNOWLEDGMENT We thank Mary Jackson for her clerical support and Patrick Ding, Ann Chen, and Peter Tai for their help with this project.

OPEN ACCESS This article is distributed under the terms of the Creative Commons Attribution Noncommercial License which permits any noncommercial use, distribution, and reproduction in any medium, provided the original author(s) and source are credited.

\section{REFERENCES}

1. Fisher B, Bauer M, Margolese R, et al. Five-year results of a randomized clinical trial comparing total mastectomy and segmental mastectomy with or without radiation in the treatment of breast cancer. N Engl J Med. 1985;312:665-73.

2. Anonymous NIH consensus conference. Treatment of early-stage breast cancer. J Am Med Assoc. 1991;265:391-5.

3. Fisher B, Anderson S, Bryant J, et al. Twenty-year follow-up of a randomized trial comparing total mastectomy, lumpectomy, and lumpectomy plus irradiation for the treatment of invasive breast cancer. N Engl J Med. 2002;347:1233-41.

4. Cunnick GH, Mokbel K. Skin-sparing mastectomy. Am J Surg. 2004;188:78-84.

5. Gerber B, Krause A, Reimer T, et al. Skin-sparing mastectomy with conservation of the nipple-areola complex and autologous reconstruction is an oncologically safe procedure. Ann Surg. 2003;238:120-7.

6. Sacchini V, Pinotti JA, Barros AC, et al. Nipple-sparing mastectomy for breast cancer and risk reduction: oncologic or technical problem? J Am Coll Surg. 2006;203:704-14.

7. Petit JY, Veronesi U, Orecchia R, et al. Nipple sparing mastectomy with nipple areola intraoperative radiotherapy: one thousand and one cases of a five years experience at the European Institute of Oncology of Milan (EIO). Breast Cancer Res Treat. 2009; 117:333-8.

8. Gerber B, Krause A, Dieterich M, Kundt G, Reimer T. The oncological safety of skin sparing mastectomy with conservation of the nipple-areola complex and autologous reconstruction: an extended follow-up study. Ann Surg. 2009;249:461-8.

9. Santini D, Taffurelli M, Gelli MC, et al. Neoplastic involvement of nipple-areolar complex in invasive breast cancer. Am J Surg. 1989;158:399-403.

10. Menon RS, van Geel AN. Cancer of the breast with nipple involvement. Br J Cancer. 1989;59:81-4.

11. Verma GR, Kumar A, Joshi K. Nipple involvement in peripheral breast carcinoma: a prospective study. Indian J Cancer. 1997;34: $1-5$.
12. Smith J, Payne WS, Carney JA. Involvement of the nipple and areola in carcinoma of the breast. Surg Gynecol Obstet. 1976;143:546-8.

13. Crowe JP Jr, Kim JA, Yetman R, Banbury J, Patrick RJ, Baynes D. Nipple-sparing mastectomy: technique and results of 54 procedures. Arch Surg. 2004;139:148-50.

14. Caruso F, Ferrara M, Castiglione G, et al. Nipple sparing subcutaneous mastectomy: sixty-six months follow-up. Eur J Surg Oncol. 2006;32:937-40.

15. Andersen JA, Pallesen RM. Spread to the nipple and areola in carcinoma of the breast. Ann Surg. 1979;189:367-72.

16. Wertheim U, Ozzello L. Neoplastic involvement of nipple and skin flap in carcinoma of the breast. Am J Surg Pathol. 1980;4: 543-9.

17. Li W, Wang S, Guo X, et al. Nipple involvement in breast cancer: retrospective analysis of 2323 consecutive mastectomy specimens. Int J Surg Pathol. 2011;19:328-34.

18. Laronga C, Kemp B, Johnston D, Robb GL, Singletary SE. The incidence of occult nipple-areola complex involvement in breast cancer patients receiving a skin-sparing mastectomy. Ann Surg Oncol. 1999;6:609-13.

19. Sikand K, Lee AH, Pinder SE, Elston CW, Ellis IO. Sections of the nipple and quadrants in mastectomy specimens for carcinoma are of limited value. J Clin Pathol. 2005;58:543-5.

20. Cense HA, Rutgers EJ, Lopes Cardozo M, Van Lanschot JJ. Nipple-sparing mastectomy in breast cancer: a viable option? Eur J Surg Oncol. 2001;27:521-6.

21. Simmons RM, Brennan M, Christos P, King V, Osborne M. Analysis of nipple/areolar involvement with mastectomy: can the areola be preserved? Ann Surg Oncol. 2002;9:165-8.

22. Lagios MD, Gates EA, Westdahl PR, Richards V, Alpert BS. A guide to the frequency of nipple involvement in breast cancer. A study of 149 consecutive mastectomies using a serial subgross and correlated radiographic technique. Am J Surg. 1979;138: 135-42.

23. Brachtel EF, Rusby JE, Michaelson JS, et al. Occult nipple involvement in breast cancer: clinicopathologic findings in 316 consecutive mastectomy specimens. J Clin Oncol. 2009;27:4948-54.

24. Lester T, Wang J, Bourne P, Yang Q, Fu L, Tang P. Different panels of markers should be used to predict mammary Paget's disease associated with in situ or invasive ductal carcinoma of the breast. Ann Clin Lab Sci. 2009;39:17-24.

25. Schelfhout VR, Coene ED, Delaey B, Thys S, Page DL, De Potter CR. Pathogenesis of Paget's disease: epidermal heregulin-alpha, motility factor, and the HER receptor family. J Natl Cancer Inst. 2000;92:622-8.

26. Morimoto T, Komaki K, Inui K, et al. Involvement of nipple and areola in early breast cancer. Cancer. 1985;55:2459-63.

27. Luttges J, Kalbfleisch H, Prinz P. Nipple involvement and multicentricity in breast cancer. A study on whole organ sections. J Cancer Res Clin Oncol. 1987;113:481-7.

28. Stolier AJ, Sullivan SK, Dellacroce FJ. Technical considerations in nipple-sparing mastectomy: 82 consecutive cases without necrosis. Ann Surg Oncol. 2008;15:1341-7.

29. Voltura AM, Tsangaris TN, Rosson GD, et al. Nipple-sparing mastectomy: critical assessment of 51 procedures and implications for selection criteria. Ann Surg Oncol. 2008;15:3396-401.

30. Jensen JA, Orringer JS, Giuliano AE. Nipple-sparing mastectomy in 99 patients with a mean follow-up of 5 years. Ann Surg Oncol. 2011;18:1665-70.

31. Rusby JE, Smith BL, Gui GP. Nipple-sparing mastectomy. $B r J$ Surg. 2010;97:305-16.

32. Vyas JJ, Chinoy RF, Vaidya JS. Prediction of nipple and areola involvement in breast cancer. Eur J Surg Oncol. 1998;24:15-6.

33. Schecter AK, Freeman MB, Giri D, Sabo E, Weinzweig J. Applicability of the nipple-areola complex-sparing mastectomy: 
a prediction model using mammography to estimate risk of nipple-areola complex involvement in breast cancer patients. Ann Plast Surg. 2006;56:498-504.

34. Rusby JE, Brachtel EF, Othus M, Michaelson JS, Koerner FC, Smith BL. Development and validation of a model predictive of occult nipple involvement in women undergoing mastectomy. $\mathrm{Br}$ J Surg. 2008;95:1356-61.

35. Gulben K, Yildirim E, Berberoglu U. Prediction of occult nippleareola complex involvement in breast cancer patients. Neoplasma. 2009;56:72-5. 